\title{
A maternidade e o feminismo: diálogo com as ciências sociais"
}

\section{Lucila Scavone $e^{* *}$}

Qual a reflexão que o movimento feminista contemporâneo desenvolveu sobre a experiência da maternidade? Quais os impactos desta reflexão nas análises das ciências sociais? Para responder estas questões é necessário, primeiramente, lembrar o contexto social no qual amadureceram as idéias e o debate feminista sobre maternidade, do final dos anos 1960 aos meados da década de 1980.

Estas idéias se configuraram paralelamente às grandes mudanças ocorridas nas sociedades ocidentais pós-segunda guerra mundial: aceleração da industrialização e da urbanização; inserção crescente das mulheres no mercado de trabalho; controle da fecundidade com o advento da contracepção medicalizada (sobretudo a pílula contraceptiva).

Nos anos mais recentes há que se considerar o incremento acelerado das Tecnologias Reprodutivas (TR), as quais contribuíram para mudar o perfil da prática social da maternidade. ${ }^{1}$ Proponho-me neste artigo a resgatar as etapas desta reflexão, mostrando suas influências teóricas, seu diálogo com as ciências humanas e sociais, bem como suas tendências atuais.

\footnotetext{
* Recebido para publicação em novembro de 2001.

*** Professora Livre-Docente do Departamento de Sociologia UNESP/Araraquara.

1 FERRAND, M. A questão dos Direitos Reprodutivos na França. Revista Estudos Feministas, nº especial, Rio de Janeiro, outubro de 1994.
} 
A maternidade e o feminismo

\section{A contribuição do feminismo}

Simone de Beauvoir, filósofa e escritora francesa, publica em 1949 o Segundo Sexo, obra contundente que provoca escândalo $e$ adesões, cujas principais idéias fundamentaram $e$ desencadearam as lutas feministas hodiernas. Podemos considerar que sua obra lançou as matrizes teóricas do feminismo contemporâneo "contestando todo determinismo biológico ou destino divino retoma a perspectiva hegeliana afirmando que 'ser é tornar-se"", resultando em sua célebre idéia "não se nasce mulher, mas torna-se mulher". ${ }^{3}$

Questionando a função da maternidade no contexto do pósguerra, em que as forças conservadoras defendiam a família, a moral e os bons costumes, as teses deste livro sobre liberdade sexual, liberação da prática da contracepção e do aborto, podem ser consideradas um marco da passagem do feminismo igualitarista para a fase do feminismo "centrado na mulhersujeito" ", dando os elementos necessários para a politização das questôes privadas, que eclodiram com o feminismo contemporâneo. Um dos elementos radicais desta politização relacionava-se à maternidade, isto é, refutar o determinismo biológico que reservava às mulheres um destino social de mães. $\mathrm{A}$ maternidade começava, então, a ser compreendida como uma construção social, que designava o lugar das mulheres na família e na sociedade, isto é, a causa principal da dominação do sexo masculino sobre o sexo feminino.

Com base nesta evidência, a crítica feminista considerava a experiência da maternidade como um elemento-chave para explicar a dominação de um sexo sobre outro: o lugar das mulheres na reprodução biológica - gestação, parto, amamentação e conseqüentes cuidados com as crianças -

2 Chaperon, S. Les Années Beauvoir 1945-1970. Paris, Fayard, 2000, p.152.

3 Beauvolr, S. Le Deuxième Sexe. Gallimard, Paris, 1949, vol.II, p.185.

4 Chaperon, S. Les Années Beauvoir... Op.cit. 
determinava a ausência das mulheres no espaço público, confinando-as ao espaço privado e à dominação masculina. Ferrand e Langevin analisam como a maternidade foi, neste período do feminismo, o eixo central de explicação das desigualdades entre os sexos. ${ }^{5}$

Em um primeiro momento a maternidade foi reconhecida como um handicap (defeito natural) que confinaria as mulheres em uma bio-classe. ${ }^{6}$ Logo, a recusa da maternidade seria o primeiro caminho para subverter a dominação masculina $e$ possibilitar que as mulheres buscassem uma identidade mais ampla, mais completa e, também, pudessem reconhecer todas suas outras potencialidades.

Por exemplo, a luta política das mulheres francesas, nos anos 1970, para obter a pílula contraceptiva e o aborto como direito político, possibilitou a efetivação desta recusa. A máxima deste movimento era "un enfant, si je veux, quand je veux" ["uma criança se eu quiser, quando eu quiser"], que reivindicava o direito à livre escolha da maternidade. Por outro lado, nesta mesma década nos Estados Unidos, uma outra corrente feminista mais radical condicionava a libertação das mulheres à chegada dos bebês de proveta, supondo que, nesse momento, a maternidade não se passaria mais no corpo das mulheres. ${ }^{7}$

\footnotetext{
${ }^{5}$ FERRAND, M. e LANGEVIN, A. De l'origine de l'oppression des femmes aux "fondements" des rapports sociaux de sexe. In: BATTAGLIOla et alii. (org.) $A$ propos des rapports sociaux/ parcours épistémologiques. Paris, Centre Sociologie Urbaine/CNRS, 1990, pp.17-76.

6 Tratando-se de formulações teóricas do feminismo, torna-se difícil avaliar a extensão real destas idéias. O mais aproximativo é lembrar o importante alcance que algumas lutas pontuais tiveram na França: a luta pela contracepção livre e gratuita; a luta pela liberação do aborto, as quais, contaram com o apoio de milhares de mulheres francesas que não militavam necessariamente no movimento feminista e que reivindicavam a "livre escolha da maternidade".

7 Firestone, S. A dialética do sexo. Rio de Janeiro, Labor, 1976. Mesmo com o avanço atual das Tecnologias Conceptivas, ainda não chegamos a ponto de dispensar o corpo feminino da gestação.
} 
A maternidade e o feminismo

A luta pela livre escolha da maternidade (contracepção livre e gratuita, liberação do aborto) rompia com a premissa "tota mulier in útero", que definia a mulher pela maternidade. A aquisição deste direito era considerada fundamental para liberar as mulheres do lugar que ocupavam na vida privada, portanto, condição de liberdade e igualdade sociais. A grande novidade desta luta é que ela introduzia, do ponto de vista dos direitos humanos, a noção de direitos específicos, direitos tidos como de terceira geração. ${ }^{8} \mathrm{O}$ eixo desta luta se situa na corrente do feminismo igualitário.

Passado o impacto da recusa da maternidade vieram perguntas dentro do movimento feminista: "nós (as mulheres) queríamos ser definidas sem a maternidade? Aceitávamos ser mutiladas de uma parte de nossa história, de nossa identidade?" 9 Chega-se, então, a um segundo momento, que Ferrand e Langevin denominam "negação do handicap" ${ }^{10}$ A maternidade passa a ser considerada como um poder insubstituível, o qual só as mulheres possuem $e$ os homens invejam. ${ }^{11}$ Neste momento, a reflexão feminista também dialoga com as ciências humanas e sociais: em teses lacanianas, que valorizam o lugar das mulheres na gestação, lembrando que o cordão umbilical, unindo o feto à mãe, é fonte de vida e poder ${ }^{12}$; em teses históricas que resgatam a experiência da maternidade como parte da identidade e poder femininos ${ }^{13}$; em teses antropológicas que, analisando as manifestações culturais

\footnotetext{
8 Bobbio, N. A era dos Direitos. Rio de Janeiro, Campus, 1992.

9 VILAINE, A.; GaVARINI, L.; Le CoAdic, M. Maternité en Mouvement. Grenoble e Montréal, PUG/ESM, 1986, p.10.

${ }^{10}$ Ferrand, M. e Langevin, A. De l'origine de l'oppression des femmes... Op.cit.

${ }^{11}$ IRIGARAY, L. Le corps-à-corps avec la mere. Montréal, Pleine Lune, 1981.

12 ID., IB.

${ }^{13}$ KNiBiLHER, Y. e Fouquet, C. Histoire des Mères. Paris, Montalba, 1977.
} 
da maternidade, recuperam o saber feminino que lhe está associado. ${ }^{14}$

Do ponto de vista foucaltiano todo saber tem sua gênese em relações de poder ${ }^{15}$, isto significa que, ao resgatar o saber feminino associado à maternidade, esta segunda etapa da reflexão feminista dá visibilidade ao poder que as mulheres exercem na sociedade mediante este fenômeno bio-psíquico-social que é a maternidade. Esta abordagem situa-se na corrente do feminismo diferencialista, refletindo suas lutas pela afirmação das diferenças e da identidade feminina.

Em um terceiro momento, segundo Ferrand e Langevin, ocorre a "desconstrução do handicap natural", que mostra como não é o fato biológico da reprodução que determina a posição social das mulheres, mas as relações de dominação que atribuem um significado social à maternidade. Esta argumentação coincide, também, com a expansão das Novas Tecnologias Conceptivas, as quais introduzem na reprodução humana (como todas outras tecnologias reprodutivas) a dúvida sobre um destino biológico inevitável.

Em suma, a definição teórica destes três momentos é reveladora de uma prática social - a maternidade - com todas suas contradições, mudanças e permanências. A recusa ou aceitação da maternidade pode acontecer, ao mesmo tempo, em espaços e posições sociais diferenciadas e não estão, necessariamente, ancoradas na idéia do handicap. Apesar da crítica feminista ter partido da constatação da diferença biológica entre os sexos, considerando-a um defeito, ela acaba mostrando que a dominação de um sexo sobre o outro só pode ser explicada social e não biologicamente. ${ }^{16}$

\footnotetext{
${ }^{14}$ Kitzinger, S. Mães um estudo antropológico da maternidade. Portugal/Brasil, Presença/Martins Fontes, 1978.

${ }^{15}$ Foucault, M. Microfísica do Poder. Rio de Janeiro, Graal, 1979.

${ }^{16}$ FerRand, M. e LANGeVin, A. De l'origine de l'oppression des femmes... Op.cit.
} 
A maternidade e o feminismo

Neste ponto, a reflexão feminista muito contribuiu para a compreensão do fenômeno social da maternidade dentro ou fora da família, ultrapassando - mediante a utilização do conceito de gênero - as interpretações sociológicas que, a partir das décadas de 1960 e 1970, buscavam a origem das diferenças sociais entre os sexos na linha bio-determinista. ${ }^{17} \mathrm{Ou}$, ainda, àquelas que, a exemplo da "teoria dos papéis" parsoniana, atribuíam à mulher um papel expressivo dentro da família (pois ela exprimiria melhor a vida afetiva da mesma) e ao homem um papel instrumental (de ligação à sociedade $e$ de provedor dos bens da família), possibilitando-nos pensar a maternidade como parte deste papel, o que contribuiria para o funcionamento do sistema social. ${ }^{18}$

Foi com a introdução do conceito de gênero nas ciências sociais "empreendida pelas feministas contemporâneas (...), para insistir sobre a inadequação das teorias existentes em explicar as desigualdades persistentes entre os homens e as mulheres"19 que alcançamos uma compreensão relacional da maternidade, respondendo pela construção social das diferenças entre os sexos. Não podemos compreender a maternidade sem abordar a paternidade, a mãe sem o pai, no sentido biológico e social do termo.

A perspectiva de gênero nos possibilitou abordar a maternidade em suas múltiplas facetas. Ela pôde ser abordada tanto como símbolo de um ideal de realização feminina, como também, símbolo da opressão das mulheres, ou símbolo de poder das mulheres, e assim por diante, evidenciando as inúmeras possibilidades de interpretação de um mesmo símbolo. Além disso, ela pôde ser compreendida como constituinte de um tipo de

\footnotetext{
${ }^{17}$ Sullerot, E. Les françaises au travail. Paris, Hachette, 1973; e [sous la direction de] Le fait féminin. Qu' est-ce qu'une femme? Paris, Fayard, 1978.

${ }^{18}$ PARSONS, T. e BALES, R. Family, socialization and Interaction Process. NY, Free Press, 1955.

${ }^{19}$ ScotT, J. Gênero: uma categoria útil de análise histórica. Educação e Realidade, n 16 , vol.2, Porto Alegre, jul-dez 1990, p.13.
} 
organização institucional familiar, cujo núcleo central articulador é a família. E, mais ainda, foi possível compreende-la como um símbolo construído histórico, cultural e politicamente resultado das relações de poder e dominação de um sexo sobre o outro. Esta abordagem contribuiu para a compreensão da maternidade no contexto cada vez mais complexo das sociedades contemporâneas.

\section{A maternidade na era tecnológica}

A questão da realização da maternidade - ter ou não filha/os, ser ou não ser mãe; quanto/as, quando, como; quem cuida do/as filhos; enfim, todas estas aflitivas questões ainda com grandes conseqüências para a vida das mulheres - ganhou novos rumos com o incremento das TR (contraceptivas e conceptivas), que possibilitaram às mulheres romper com o destino inevitável que a maternidade lhes designava. Produto das relações sociais de dominação, o uso destas tecnologias mereceu inúmeros estudos entre as feministas, cientistas sociais, e cabe aqui discuti-las somente para estabelecer sua relação $e$ impactos com a maternidade. ${ }^{20}$ Sob a ótica de gênero, esta reflexão implica em analisarmos o significado da maternidade no contexto das TR, no qual as mulheres podem - dentro dos limites de suas situações sociais -, mais do que nunca, escolher.

Com as TR passamos de uma recusa circunstancial da maternidade para a possibilidade de escolha, significando, também, para as mulheres a decisão ou adequação entre vida profissional e vida familiar. As TR expressam claramente um tipo

\footnotetext{
${ }^{20}$ Não se trata de aderir cegamente à razão tecnológica (diga-se de passagem, razão dominante), muito menos de nostalgicamente querer voltar a um passado onde as relações com a natureza eram mais diretas, mas de reconhecer que, ao discutirmos os contornos da maternidade hoje (seja no nordeste ou sul do Brasil, na França, ou em qualquer outro país), constataremos os impactos que as TR causaram nos padrões de maternidade. Ver SCAVONE, L. Feminismo e Ciências Sociais. Tese de Livre Docência, UNESP, Araraquara, 2001.
} 
A maternidade e o feminismo

de relação com a maternidade, construída histórica, social, política, culturalmente com base em uma mesma razão: a de que existe uma solução tecnológica para a reprodução humana.

Não querendo filhos/as, as mulheres (e seus companheiros) recorrem às tecnologias contraceptivas; ao tê-los, recorrem ao parto cirúrgico; ao querê-los recorrem às tecnologias conceptivas, construindo um verdadeiro ciclo de uso das TR para a realização ou não da maternidade. Este ciclo se constrói, também, a partir da constatação de que o uso de uma tecnologia pode gerar a necessidade do uso de outra: por exemplo, o aumento da esterilização no mundo e seu alto índice no Brasil, entre mulheres jovens, provoca uma busca mais freqüente pela concepção artificial, alimentando o consumo da reprodução assistida (RA). ${ }^{21}$

As mulheres brasileiras entraram no modelo de família moderno pela via de uma recusa definitiva da maternidade. A queda abrupta da natalidade foi um dos grandes impactos dos últimos anos na mudança de padrão de maternidade no país - o número de filho/as por mulher passou de 4,5 em 1980 para 2,5 em 1996 - por meio de uma intensa política de controle demográfico, com a generalização abusiva da esterilização feminina. ${ }^{22}$ Se a maioria delas ainda têm seus filho(a)s na faixa etária jovem, elas também interrompem definitivamente a opção da maternidade cada vez mais jovens e até com poucos filho(a)s. De fato, $24,3 \%$ das mulheres brasileiras esterilizadas têm entre 20-29 anos e $24 \%$ do total de mulheres esterilizadas, têm dois filho(a)s e $3 \%$ um filho(a). ${ }^{23}$ Também já foi observado um recuo na decisão do primeiro filho: no Estado de São Paulo, 58,4\% das mulheres têm filho(a)s entre 20-29 anos; 6,5\% têm filho(a)s entre 35-39 anos. ${ }^{24}$ Estas últimas são mulheres profissionais que esperam primeiro

\footnotetext{
${ }^{21}$ ID., IB.

${ }^{22}$ LeRidon, L. e TOULEMAN, H. La régulation des naissances se géneralise. Les Dossiers du CEPED, n 41, Paris, juin. 1996, pp.10-14.

${ }^{23}$ BENFAM e PNDS, Rio de Janeiro, 1997, pp.48-69.

${ }^{24}$ Dados da Fundação SEADE, 1993.
} 
alcançar uma estabilidade e independência financeira, para depois realizar a maternidade.

Se o modelo da maternidade reduzida pôde diminuir a ambigüidade entre vida profissional e vida familiar, ele não a esgotou. A realização da maternidade ainda é um dilema para as mulheres que querem seguir uma carreira profissional, já que, nas responsabilidades parentais, ainda são elas as mais sobrecarregadas. Não seria este um dos fatores relevantes para as mulheres recorrerem a recursos radicais como a esterilização $e o$ aborto, decidindo pela não-maternidade? ${ }^{25}$

Por outro lado, a expansão da reprodução assistida no país e no mundo evidencia que o projeto de maternidade continua presente na vida das mulheres. Com este recurso tecnológico a maternidade biológica já não é mais o primeiro critério que designa uma mãe, ao passo que a paternidade biológica pode ser referida a origem do espermatozóide. A fragmentação do papel de mãe é um dos impactos evidentes para o que é chamado de familia artificial. ${ }^{26}$ Os tipos de mãe portadora, analisados por Laborie $^{27}$, nos dão uma idéia das novas configurações da maternidade: mãe portadora simples, a mulher inseminada pelo esperma do futuro pai social, levando a gravidez a termo e dando a criança ao casal que a solicitou; mãe portadora verdadeira (assim denominada pelos médicos), mulher fértil no útero da qual são implantados um ou vários embriões obtidos pela FIV com os óvulos e espermas das pessoas que vão educar a criança. Esta mãe vai assegurar a gestação da criança $e$ ao seu nascimento entregá-la para os pais. Este imbróglio de papéis, não só pode

${ }^{25}$ SCAVONE, L. Feminismo e Ciências Sociais. Op.cit.

${ }^{26}$ SNOWden, R.; Mitchell, G. D. La famille artificielle, reflexion sur I'insemination artificielle par donneur. Paris, Ed. Antropos, 1984. Segundo estes autores, esta seria a família constituída com os/as personagens envolvidos na RA.

${ }^{27}$ LABORIE, F. Rapports Sociaux des Sexe dans les Nouvellles Techonologies de la reproducion. Cahiers du GEDISST, n 3, Paris, IRESCO/CNRS, 1992, pp.29-36. 
A maternidade e o feminismo

causar problemas de ordem ética ${ }^{28}$, jurídica para os quais novas legislações estão em elaboração, como também pode causar impacto na própria definição dos papéis familiares clássicos: a concepção não se limitará mais aos genitores, já que pode ser independente do ato sexual. ${ }^{29}$

É possivel afirmar que um dos aspectos mais evidentes na transformação da maternidade foi o rompimento com seu determinismo biológico. Este rompimento levou à separação definitiva da sexualidade com a reprodução, seja pela contracepção medicalizada, seja pela reprodução artificial, $e$ desconstruiu a equação mulher=mãe, construindo uma outra equação mais complexa, onde entram em cena também a classe médica $e$ as novas tecnologias. A "maternidade artificial", ou a "parentalidade artificial" já são as fórmulas do presente do(a)s indivíduos estéreis que se ampliarão no futuro, com suas imbricadas implicações éticas, médicas, políticas, além das prováveis conseqüências à saúde das mulheres. ${ }^{30}$

A crítica feminista contribuiu para o questionamento mais profundo, sob a ótica de gênero, sobre o "lugar da mãe" em relação ao "lugar do pai" na família e sociedade. Esta crítica foi se

\footnotetext{
${ }^{28}$ Segundo Parseval, as duas principais questões éticas na França: o anonimato e a gratuidade dos doadores de esperma não garantem por si uma postura ética; o anonimato, segundo ela, protege os interesses dos médicos e de alguns pais, mas não o das crianças que vão nascer, que jamais terão acesso às raízes. Por outro lado, ela lembra que se o doador não recebe remuneração, o esperma, tal qual um remédio, é reembolsado pelo seguro social na França. DELAISI DE PARSEVAL, G. Questions sur don sans échange. Dialogue, Recherches cliniques et sociologiques sur le coupie et la familie, Paris, 1992, p.115. Ver também, LABORIE, F. De quelques faces cachés des nouveilles tecniques de procréation. In: L'ovaire-dose. Les nouvelles méthodes de Procréation. Paris, Syros/Alternatives, 1989, p.89.

${ }^{29}$ NovaES, S. Les tecnhiques medicales de procréation. DE SingLY, F. (org.) La famille: I'état des savoirs. Paris, La Découvert, 1991, pp.327-333.

${ }^{30}$ LABORIE, F. Procréation artificielle: santé des femmes et des enfants. In: MASUYStroobant, G. et alii. Santé et Mortalité des Enfants en Europe: Inégalités Sociales D'hier et D'aujourd'hui. Paris, L'Harmattan, 1996, pp.477-500.
} 
renovando, acompanhando todas as mudanças referidas, as quais se aceleraram na última década; com isto, os estudos feministas sobre a maternidade tomaram uma nova direção, utilizando tanto os conceitos de relaçóes sociais de sexo, como de gênero. ${ }^{31}$

Em primeiro lugar, estes estudos se tornaram mais escassos, principalmente enquanto reflexão mais abrangente sobre o lugar da maternidade: não se discute mais se ela é o eixo central da dominação masculina. As pesquisas e reflexões do período mais recente centram-se nas questões mais específicas dos usos das tecnologias reprodutivas e suas conseqüências à saúde das mulheres: contracepção, esterilização, aborto, cesariana, nos países do sul, e novas tecnologias de concepção, nos países do norte.

Uma das grandes questões que suscitam estas reflexões têm a ver com a ingerência crescente da medicina na procriação: "a reprodução não estaria escapando progressivamente das mulheres?" ${ }^{32}$ Esta inquietação remete, implicitamente, a uma postura positiva diante da maternidade: uma experiência feminina importante, cujo controle não deve escapar às mulheres. Por outro lado, ela coloca a questão da maternidade no bojo de uma discussão mais ampla sobre os impactos das novas tecnologias nas sociedades modernas, reavivando a polêmica sobre a relação

\footnotetext{
${ }^{31}$ Este conceito, utilizado principalmente na literatura feminista francesa, pressupõe a "hierarquia social entre os sexos que implica numa relação de dominação dos homens sobre as mulheres". Mais adiante afirma que "as relações sociais de sexo constituem a estrutura que gera, organiza, a produção da vida humana e a controla em termos de qualidade e quantidade". KERGOAT, D. Des rapports sociaux de sexe et la division sexuelle du travail. Cahiers $d u$ GEDISST. Rapports sociaux de sexel une journée de discussion, Paris, IRESCO/CNRS, 1992, p.23. O conceito de gênero mais utilizado na literatura anglo-saxônica também tem esta conotação relacional, se apoiando mais na noção de poder entre os sexos.

${ }^{32}$ DANDURAND, R. B. Femmes et familles: sous le signe du paradoxe. $R F$, vol.7, $\mathrm{n}^{\circ} 1,1994$, p. 9
} 
natureza e cultura, sobretudo a partir do feminismo de inspiração ecológica. ${ }^{33}$

Em segundo lugar, outro grupo de estudos, aborda a questão da maternidade construindo $\mathrm{o}$ conceito de "parentalidade":

trata-se de estudar o posicionamento dos atores sociais dos dois sexos no processo de constituição do laço parental e não mais de partir de uma especificação a priori deste laço segundo o sexo. ${ }^{34}$

Este tipo de análise permite compreender, no seu conjunto, a relação entre os indivíduos adultos (homens e mulheres) com suas crianças. Entretanto, a maioria desses estudos constata um tipo de parentalidade, onde as mulheres continuam tendo uma relação mais comprometida com os filho(a)s do que os homens ${ }^{35}$, sendo ainda elas que assumem a maioria das responsabilidades parentais.

Por outro lado, também foram observados alguns casos de homens assumindo todas estas responsabilidades, indicando tendências de transformações nas relações parentais e nas relações de gênero. $\mathrm{O}$ resultado destas pesquisas reflete tanto as mudanças que estão ocorrendo no interior da família e sociedade, como as ambigüidades de fundo que caracterizam um período de transição de modelos.

\footnotetext{
${ }^{33}$ A corrente alemã desse feminismo sugere às mulheres uma melhor divisão das atividades profissionais e maternais, dando mais atenção aos filhos e consumindo menos. Ver os textos de MiES, M. Os modelos de Consumo no Norte: Causa da Destruição ambiental e da pobreza no sul. Cadernos da REDEH, ano I, n ${ }^{\circ}$ Especial, 1991. Esta proposta vem de encontro com a gestão de maior autonomia na vida privada discutida por GoRz, A. Capitalisme, Socialisme, Ecologie. Paris, Galilée, 1991.

${ }^{34}$ Combes, D. e Devreux, A.M. Construire sa Parenté. Paris, CSU, 1991, p.5.

${ }^{35}$ ID., IB.; COURNOYER, M. Maternité biologique, maternité sociale. Des stratégies d'educatrices professionnelles. $R F$, vol.7, n 1 , Québec, 1994.
} 
Entre o modelo reduzido de maternidade com uma variedade crescente de tipos de mães (mães donas-de-casa, mães chefes-de-família, mães "produção independente", casais "igualitários") e as diversas soluções encontradas para os cuidados das crianças (escolas com tempo integral, creches públicas, babás, escolinhas especializadas, vizinhas que dão uma olhadinha, crianças entregues a seus próprios cuidados, avós solícitos), a maternidade vai se transformando, seguindo tanto as pressões demográficas, natalistas ou controlistas, como as diferentes pressões feministas e os desejos de cada mulher.

A escolha reflexiva para aceitação ou não da maternidade (da paternidade, ou da parentalidade) constitui-se em um elemento deste período de transição, possibilitando às mulheres $e$ aos homens que a decisão pela reprodução seja feita com base na experiência adquirida, sem medo, culpa, ou qualquer sentimento de não-realização individual e/ou social. Evidentemente, esta escolha será tanto mais reflexiva quanto maior a possibilidade de acesso à informação, à cultura e ao conhecimento especializado.

Este novo modelo, que ora já se esboça, têm diversas nuanças e se define com mais ou menos força de acordo com a classe social e com o país a que está referido. É o modelo de proles reduzidas; mulheres com carreiras profissionais; mães $e$ pais, juntos e/ou separados, produzindo e reproduzindo; casais hetero e homossexuais; mães ou pais criando seus filhos sozinhos; institucionalização dos cuidados maternos por profissionais especializados; enfim, é o modelo que busca se adequar às mudanças da vida contemporânea, ao mesmo tempo em que é forjado por estas mudanças, redesenhando o funcionamento e a estrutura da família contemporânea.

Para além dos motivos psicológicos, sócio-econômicos, que fazem as mulheres adiarem, adiantarem, aceitarem ou recusarem a maternidade, ou ainda, dos valores ideológicos e políticos que alimentam o ideal de sua realização, sempre estará em questão seu significado social. Este significado revela que, apesar das inúmeras mudanças ocorridas na situação social das mulheres, a 
A maternidade e o feminismo

realização da maternidade ainda compromete consideravelmente as mulheres e revela uma face importante da lógica da razão androcêntrica. Com toda a certeza, a maternidade ainda separa as mulheres socialmente dos homens e pode até legitimar, em determinados contextos, a dominação masculina. Esta constatação, bem como os impactos das TR à saúde das mulheres, talvez sejam as contribuições mais importantes do feminismo aos estudos científicos sobre a maternidade. Exercício de não passividade diante das facilidades tecnológicas e de dúvida sobre as possibilidades mágicas de solucionar problemas reprodutivos. 